\title{
Natural Orifice Non-Descent Hysterectomy - Revisiting Fading Surgical Art
}

\author{
Shashi Prateek ${ }^{1}$, Jaya Chaturvedi², Latika Chawla ${ }^{3}$, Shailja Sharma ${ }^{4}$, Neetu Kochhar ${ }^{5}$, \\ Deepti Chaudhary6, Rajlaxmi Mundhra7, Ankita Yadav ${ }^{8}$ \\ 1, 2, 3, 4, 5, 6, 7, 8 Department of Obstetrics and Gynaecology, All India Institute of Medical Sciences (AIIMS), \\ Rishikesh, Dehradun, Uttarakhand, India.
}

\section{ABSTRACT}

\section{BACKGROUND}

We wanted to assess the feasibility of natural orifice non-descent hysterectomy (NONH) for various benign gynaecological indications.

\section{METHODS}

This retrospective study was conducted at a tertiary care centre including patients requiring hysterectomy for various gynaecological indications over 12 months. Outcomes including time of surgery, blood loss, intraoperative surgical technique, complications, and conversion to the abdominal route were noted.

\section{RESULTS}

A total of 68 cases of natural orifice non-descent hysterectomy were performed. The uterine fibroid was the most common (50\%) indication for surgery followed by adenomyosis. Uteri with previous multiple surgeries were also successfully operated vaginally. The average surgical time was $60 \mathrm{~min}$, with minimal blood loss. Post-operative recovery was good and patients were discharged after 48 hours.

\section{CONCLUSIONS}

This article concludes that natural orifice is a safe route of non-descent hysterectomy even for larger and scarred uteri using various debulking and surgical techniques but requiring good anatomical knowledge, surgical expertise and teamwork.

\section{KEY WORDS}

Natural Orifice Non-Descent Hysterectomy (NONH); Surgical Variations; Debulking Technique; Post-Operative Recovery.
Corresponding Author: Dr. Shailaja Sharma, Senior Resident, Department of OBG, All India Institute of Medical Sciences, (AIIMS), Rishikesh, Uttarakhand, India. E-mail: shailjasharmahw@gmail.com

DOI: $10.14260 /$ jemds/2021/764

How to Cite This Article:

Prateek S, Chaturvedi J, Chawla L, et al. Natural orifice non-descent hysterectomy revisiting fading surgical art. J Evolution Med Dent Sci 2021;10(44):3781-3784, DOI: $10.14260 / \mathrm{jemds} / 2021 / 764$

Submission 18-06-2021, Peer Review 18-11-2021, Acceptance 25-11-2021, Published 30-11-2021.

Copyright (C) 2021 JEMDS. This is an open access article distributed under Creative Commons Attribution License [Attribution 4.0 International (CC BY 4.0)] 


\section{BACKGROUND}

In this modern era of medical science, surgical skills and techniques are fast evolving. With the advent of endoscopic approaches, surgeons can achieve results similar to open approaches giving minimal scar to the patient. This less amount of scarring brings better patient satisfaction and compliance to surgery. Taking it forward, the approach of surgery is moving from "keyhole" to "no hole" technique, thus making it more patient compliant but at the same time challenging for the surgeons. Gynaecologists had been practising this art of no hole technique for a hysterectomy for very long with promising results but the commencement of endoscopic approaches has led them to forget this art. Hysterectomy is the most common gynaecological surgery and second after caesarean section.1,2 It can be performed through abdominal, natural orifice (vaginal) or endoscopic (laparoscopic \& robotic) routes. Previously, abdominal route was used to remove the uterus which gave an additional advantage to inspect ovaries. The vaginal route was used for pelvic organ prolapse. In absence of prolapse, the abdominal route was preferred over the vaginal route for hysterectomy. As now the emphasis is on minimally invasive surgery, there is a slow rise in vaginal hysterectomy for non-prolapse indications that is non-descent vaginal hysterectomy. Natural orifice hysterectomy (NONH) is considered better than abdominal, laparoscopic or robotic hysterectomy as it is associated with faster patient recovery and early return to the normal daily routine. An additional benefit of non-descent vaginal hysterectomy is that there is less chance of postoperative paralytic ileus as it is an extraperitoneal surgery with minimal bowel handling. As non-descent vaginal hysterectomy is a scarless surgery with decreased risk of paralytic ileus it should be preferred by all surgeons as primary surgery for benign cases. Non-descent vaginal hysterectomy is a safe, effective and economical surgery. Complications like infection, dehiscence, evisceration, hernia and scar discomfort are less in NDVH and morbidity is also reduced. As compared to open surgery there is an early return of bowel functions, early ambulation, reduced need for medication, hence NDVH is a better option for the elderly, obese and patients with other comorbidities. Also, it can be performed with lower health care costs compared to endoscopic surgery. ${ }^{3}$ Cosmetically, a scarless surgery is always better. $\mathrm{NOH}$ is more challenging for the surgeon as $\mathrm{s} /$ he has limited space to operate, requiring good anatomical knowledge and surgical expertise, but abdominal hysterectomy requires less training and there is a lack of awareness among the public about different routes and lack of enthusiasm among gynaecologists and hence abdominal route is preferred. Every patient should be informed and counselled about every possible option regarding the routes of hysterectomy by a gynaecologist that will help them to make a better decision, as most of the patients are not even aware of the possible routes of hysterectomy.

This study intended to report the personal experience of performing challenging cases of non-descent uteri using various debulking techniques like uterine bisection, wedge resection, myomectomy or a combination of any of these. And also emphasising that a natural orifice hysterectomy is a safe option for large and scarred uteri.

\section{METHODS}

This is a retrospective study conducted in a tertiary care centre. Demographic and clinical data of patients that underwent natural orifice non-descent vaginal hysterectomy (NONH) from January 2019 to December 2019 were extracted from clinical case sheets. Data were plotted on an excel sheet. The study was performed after receiving ethical approval from the Department of Obstetrics and Gynaecology, AIIMS Rishikesh, Dehradun, Uttarakhand, Patients who underwent NONH for benign indications of uterus up to a 24-week period of gestation size were included in the study. Surgeries performed for prolapse, malignancy, complex adnexal masses and uterine size $>24$ weeks were excluded from the study. Demographic, clinical and surgical details were recorded and evaluated.

\section{Operative Technique}

The preferred mode of anaesthesia for surgery was regional (spinal or epidural). General anaesthesia was given to selected patients requiring it for medical reasons. Patients were placed in the lithotomy positions. After cleaning and draping, patients were re-examined under the effect of anaesthesia to assess the uterine size, mobility and location of the fibroid. After applying labial sutures, bladder was catheterized, Sim's speculum was inserted to retract the posterior vaginal wall.

Cervix was held with vullsellum. Various surgical techniques used are described below:

1. In non-scarred uteri, a circumferential incision on the cervix was given. Pubovesicocervical ligament was cut and the bladder was dissected. The anterior pouch was opened first followed by the posterior pouch.

2. In previously scarred uteri, the posterior pouch was opened first, followed by pushing up the bladder separating it carefully from the anterior uterine wall. Clamps were applied up to the uterine artery, thereby the uterus was delivered posteriorly and corneal structures were clamped. An anterior pouch was opened in the end.

3. For larger uteri, owing secondarily to fibroids, the anterior pouch was opened first, the bladder was pushed up followed by the posterior. After ligating both uterine arteries, myomectomy was performed to reduce the size of the uterus.

4. Also, in other cases, uterine bisection and wedge resection was done after opening both pouches. In wedge resection, with simultaneous clamping of ligaments, uterine chunks were removed to reduce the size and to bring the larger uterus down.

To remove the ovaries, infundibulopelvic ligament was clamped, cut and ligated after delivering the uterus. Intraoperative blood loss, surgery time and intra-operative and post-operative complications were recorded. All patients received a single dose of ceftriaxone preoperatively followed by oral antibiotics for a total of five days after surgery. In uncomplicated cases, urinary catheter was removed after 24 hours and patients were discharged under satisfactory conditions after 48 hours. 


\section{Statistical Analysis}

Simple mathematics for the calculation of percentage was used and no specific statistical analysis was used.

\section{RESULTS}

A total of 68 patients were operated and Table 1 is showing the distribution of cases according to their age, body mass index and parity. The majority (41.1\%) of cases were among the age group of 45-50 years. In these patients, major pathology was uterine fibroid followed by adenomyosis. Out of 68 cases, $16.1 \%$ of women were grand multipara, $36.7 \%$ with parity of $2,25 \%$ were para3. 2 nulligravida patients were also operated on for fibroid uterus. Tight introitus giving limited surgical space with multiple fibroids makes it more challenging for the surgeon.

\begin{tabular}{|cccc|}
\hline Parameters & $\begin{array}{c}\text { Years/ KG/M } \\
\text { Parity }\end{array}$ & $\begin{array}{c}\text { Number of } \\
\text { Patients }\end{array}$ & Percentage \\
& $35-40$ & 4 & $5.8 \%$ \\
Age (in years) & $40-45$ & 20 & $29.4 \%$ \\
& $45-50$ & 28 & 41.1 \\
& $50-55$ & 12 & 17.6 \\
& $>55$ & 4 & $5.8 \%$ \\
BMI $\left(\mathrm{kg} / \mathrm{m}^{2}\right)$ & $<20$ & 3 & $4.4 \%$ \\
& $20-25$ & 17 & $25 \%$ \\
& $25-30$ & 22 & $32.3 \%$ \\
& $30-35$ & 21 & $30.8 \%$ \\
& $>35$ & 5 & $7.3 \%$ \\
Parity & Nulliparous & 2 & $2.9 \%$ \\
& 1 & 13 & $19.11 \%$ \\
& 2 & 25 & $36.7 \%$ \\
& 3 & 17 & $25 \%$ \\
& $>3$ & 11 & $16.1 \%$ \\
\hline \multicolumn{3}{c}{ Table 1. Demographic Profile } \\
\hline
\end{tabular}

\begin{tabular}{|c|c|c|c|}
\hline & & $\begin{array}{c}\text { No. of } \\
\text { Patients }\end{array}$ & Percentage \\
\hline \multirow{5}{*}{ Indication } & Fibroid & 34 & $50 \%$ \\
\hline & Adenomyosis & 18 & $26.4 \%$ \\
\hline & CIN & 6 & $8.8 \%$ \\
\hline & Endometrial hyperplasia & 6 & $8.8 \%$ \\
\hline & Chronic PID & 4 & $5.8 \%$ \\
\hline \multirow{5}{*}{$\begin{array}{l}\text { Size of uterus (period } \\
\text { of gestation size) }\end{array}$} & $<8$ & 16 & $23.5 \%$ \\
\hline & $8-12$ & 18 & $26.4 \%$ \\
\hline & $12-16$ & 22 & $32.3 \%$ \\
\hline & $16-20$ & 11 & $16.1 \%$ \\
\hline & $>20$ & 3 & $4.4 \%$ \\
\hline \multirow{4}{*}{ Previous surgery } & None & 40 & $58.8 \%$ \\
\hline & 1 & 20 & $29.4 \%$ \\
\hline & 2 & 6 & $5.8 \%$ \\
\hline & 3 & 2 & $4.4 \%$ \\
\hline \multirow{4}{*}{$\begin{array}{l}\text { Debulking } \\
\text { Technique }\end{array}$} & Uterine bisection & 34 & $50 \%$ \\
\hline & Myomectomy & 24 & $35.2 \%$ \\
\hline & Wedge resection & 4 & $5.8 \%$ \\
\hline & $\begin{array}{l}\text { Combination of the above } \\
\text { techniques }\end{array}$ & 48 & $70.5 \%$ \\
\hline Average surgical time & $60 \mathrm{~min}$ & & \\
\hline Average Blood loss & $160 \mathrm{ml}$ & & \\
\hline Hospital stays & 48 hours & & \\
\hline \multirow{4}{*}{ Complications } & Bladder injury & 1 & $1.4 \%$ \\
\hline & Vault hematoma & 1 & $1.4 \%$ \\
\hline & Secondary haemorrhage & 1 & $1.4 \%$ \\
\hline & $\begin{array}{c}\text { Conversion to abdominal } \\
\text { hysterectomy }\end{array}$ & 2 & $2.9 \%$ \\
\hline
\end{tabular}

Table 2 describes the various indications, size of the uterus, intra and postoperative outcomes. Out of 68 cases, 50 $\%$ of cases were done for uterine fibroids (submucosal, intramural \& subserosal fibroids), 18 (26.4\%) cases were operated for adenomyotic uterus followed by 6 cases each (8.8 \%) for endometrial hyperplasia \& CIN (Cervical intraepithelial neoplasia) and 4 were operated for chronic pelvic inflammatory disease. 22 patients $(32.3 \%)$ had a uterine size of $12-16$ weeks \& 11 cases were of $16-20$ week size, which is secondary to the fact that the fibroid was the major indication for surgery followed by adenomyosis. 3 (4.4 $\%)$ patients had uterine size more than 20 weeks.

Also, NONH was performed in patients with a history of various uterine surgeries including caesarean section, myomectomy, and uterine horn resection. 20 patients had a history of previous uterine surgery (caesarean, myomectomy etc). In patients with 2 or more surgeries, the bladder was found densely adhered to the anterior uterine surface. Out of various debulking techniques, uterine bisection was the most commonly used technique followed by myomectomy. A combination of the above techniques was also frequently used for larger uteri. Wedge resection was helpful in cases with restricted mobility.

The average surgical time was $60 \mathrm{~min}$. Blood loss during surgery was minimal $(160 \mathrm{ml})$ and patients were discharged from the hospital under satisfactory condition after 48 hours of surgery. One case of NONH was converted to laparotomy intraoperatively for bladder repair and in another patient, the abdomen was opened on POD 2 owing to a secondary haemorrhage. 1 patient presented with a complaint of bleeding per vaginum on POD10 \& was readmitted with the diagnosis of vault hematoma. The patient was conservatively managed with antibiotics and haemostatic agents.

\section{DISCUSSION}

Out of the 68 NONH performed, only 2 cases (2.9\%) were converted to abdominal hysterectomy which is comparable to the study conducted by Kumar et al. ${ }^{4}$ with a success rate of 95 $\%$. Among the various indications of hysterectomy, the uterine fibroid was a major indication. This is an eye-opener to the surgeon that the vaginal route can be a safe and feasible route for hysterectomy even in larger uteri. Unger et al. have also reported successful removal of uterus of up to 20 weeks $^{3}$ Various debulking techniques like bisection, myomectomy and wedge resection were used. Davies et al. ${ }^{5}$ and Mazdisnian et al. ${ }^{6}$ have also described similar reduction techniques. Also, a history of multiple previous uterine surgeries should not be considered as rejection for vaginal access. In our experience, in these cases of bladder densely adhering to the anterior uterine wall, the posterior pouch was opened first, followed by careful separation of the bladder. During bladder dissection and opening the anterior pouch, remaining close to the uterine surface is the key. Blood loss during the surgery is very minimal. A Cochrane systemic review conducted by Nieboer et al. which included 9 randomised control trials by Ottosen, Benassi, Hwang, Miskry, Garry, Ribeiro, Silva Filho, Nasira, and Gayak et al. concluded that vaginal hysterectomy was better than abdominal and laparoscopic hysterectomy in intraoperative and postoperative outcomes. ${ }^{7-15}$ ACOG also recommends that patients with uteri size less than 12 weeks should be offered vaginal route surgery, owing to lesser intraoperative complications than laparoscopic. ${ }^{16}$ The common belief that endoscopic approach for a larger uterus, chronic PID, history of previous multiple uterine surgeries is a better option should be re-evaluated. Endoscopic routes have a higher incidence of anaesthetic \& intraoperative complications, require more surgical time, expensive equipment and 
training. ${ }^{17}$ Limited surgical space in natural orifice hysterectomy can be challenging to the surgeon but with good anatomical knowledge, surgical skill and a good team, NONH experience can be ice breaking. Also being scarless and associated with faster postoperative recovery brings immense patient satisfaction which is quite rewarding to the surgeon.

\section{CONCLUSIONS}

The natural orifice is safe and a feasible option for women requiring hysterectomy of non-descent uteri for benign indications. Even large size and multiple scarred uteri can also be safely hysterectomized through this route. It is associated with minimal blood loss during surgery, a low rate of anaesthetic \& intraoperative complications, less postoperative pain and early return to daily routine activities of the patient. Being scarless brings better patient satisfaction and more surgical compliance. A good pre-operative assessment, firm determination and skilled surgical team can change the scenario of modern-day methods of hysterectomy.

Data sharing statement provided by the authors is available with the full text of this article at jemds.com.

Financial or other competing interests: None.

Disclosure forms provided by the authors are available with the full text of this article at jemds.com.

\section{REFERENCES}

[1] Bernstein SJ, McGlynn EA, Siu AL, et al. The appropriateness of hysterectomy. A comparison of care in seven health plans. Health maintenance organization quality of care consortium. JAMA 1993:269(18):2398402.

[2] Grave EJ, Gillum BS. 1994 Summary. National hospital discharge survey. Advance data from vital and health statistics No 278. National Center for Health Statistics Hyattsville, Maryland 1996.

[3] Ransom SB, McNeeley SG, White C, et al. A cost analysis of endometrial ablation, abdominal hysterectomy, vaginal hysterectomy and laparoscopy-assisted vaginal hysterectomy in the treatment of primary menorrhagia. J Am Assoc Gynaecol Laparosc 1996;4(1):29-32.

[4] Sushil K, Antony ZK. Vaginal hysterectomy for benign nonprolapsed uterus. Initial Experience. J Obstet Gynaecol Ind 2004;54(1):60-3.
[5] Davies A, Vizza E, Bournas $N$ et al. How to increase the proportion of hysterectomies performed vaginally. Am J Obstet Gynecol 1998;179(4):1008-12.

[6] Mazdisnian F, Kurzel RB, Coe S et al. Vaginal hysterectomy by uterine morcellation: an efficient, nonmorbid procedure. Obstet GynecoI 1995;86(1):60-4.

[7] Nieboer TE, Johnson N, Lethaby A, et al. Surgical approach to hysterectomy for benign gynaecological disease. Cochrane Database Syst Rev 2009;(3):CD003677.

[8] Ottosen C, Lingman G, Ottosen L. Three methods for hysterectomy: a randomized, prospective study of short term outcome. BJOG 2000;107(11):1380-85.

[9] Benassi L, Rossi T, Kaihura CT, et al. Abdominal or vaginal hysterectomy for enlarged uteri: a randomized clinical trial. Am J Obstet Gynecol 2002;187(6):1561-65.

[10] Hwang JL, Seow KM, Tsai YL, et al. Comparative study of vaginal, laparoscopically assisted vaginal and abdominal hysterectomies for uterine myoma larger than $6 \mathrm{~cm}$ in diameter or uterus weighing at least $450 \mathrm{~g}$ : a prospective randomized study. Acta Obstet Gynecol Scand 2002;81(12):1132-8.

[11] Miskry T, Magos A. Randomized prospective doubleblind comparison of abdominal versus vaginal hysterectomy in women without utero-vaginal prolapse. Acta Obstet Gynecol Scand 2003;82(4):351-8.

[12] Ribeiro SC, Ribeiro RM, Santos NC, et al. A randomized study of total abdominal, vaginal and laparoscopic hysterectomy. Int J Gynecol Obstet 2003;83(1):37-43.

[13] Garry R, Fountain J, Mason S, et al. The evaluate study: two parallel randomized trials, one comparing laparoscopic with abdominal hysterectomy, other comparing laparoscopic with vaginal hysterectomy. BMJ 2004;328(7432):129.

[14] Silva-Filho AL, Werneck RA, de Magalhães RS, et al. Abdominal vs vaginal hysterectomy: a comparative study of the postoperative quality of life and satisfaction. Arch Gynecol Obstet 2006;274(1):21-4.

[15] Dawood NS, Mahmood R, Haseeb N. Comparison of vaginal and abdominal hysterectomy: peri- and postoperative outcome. J Ayub Med Coll Abbottabad 2009;21(4):116-20.

[16] ACOG Committee Opinion. Number 311, April 2005. Appropriate use of laparoscopically assisted vaginal hysterectomy. Obstet Gynecol 2005;105(4):929-30.

[17] Richardson RE, Bournas N, Magos AL. Is laparoscopic hysterectomy a waste of time? Lancet 1995;345:36-41. 